\title{
The influence of involving citizens in all aspects of their development on social accountability in Rutsiro District-Rwanda
}

\author{
Fred K. NTAKIRUTINKA ${ }^{1}$ and Ernest SAFARI ${ }^{2}$ \\ ${ }^{1,2}$ School of Arts and Social sciences, Mount Kenya University \\ Kigali, Rwanda
}

\begin{abstract}
The aim of this research was to examine the influence of involving citizens in all aspects of their development on social accountability in Rutsiro District-Rwanda. A descriptive research design was adopted by using qualitative and quantitative approaches. The target population was 408 respondents among others local village and cell leaders who stayed in leadership for more than two years, staff and administrators of civil society organizations and local people chosen through sampling in Rutsiro District with emphasis on the government programs related to social accountability and community empowerment implemented. The sample size was calculated using Yamane formula. 202 respondents were sampled from 408 population target population that participated in the research process. The researcher gathered information using a questionnaire survey and interview guide. Data analysis was done through the use of statistical package for social sciences version 22. Ethical consideration was considered for ensuring the confidentiality and consent of respondents. Results show a strong positive correlation $(\mathrm{r}=0.842)$ between social accountability which is also significant. The researcher also concluded that participation in decision making influences social accountability in Rwanda.
\end{abstract}

Keywords: Accountability, Community, Empowerment, Community empowerment, Social accountability

\section{Introduction}

The aim of this study is to fill the gap about the performance of social accountability in Rwanda in the context of decentralization. In low percentage of intended beneficiaries that are aware of information and programs, low rate of citizens that know about activities of project -supported government, rate of grievances resolved, delay in resolving complaints, complaints satisfied with response and grievance redressed process, low rate of participation in consultation activities (National Institute of Statistics for Rwanda, 2014). How to break down these negative figures, thus becomes a difficult task.

Therefore, in search of ways to respond to social accountability across citizens, it is generally contended that effective decentralization effort requires a bottom up approach (O’Meally, 2013). In this regard, many scholars believe in, and point out to, the role of community empowerment (Shields and Rangarjan, 2013). Empirical investigation in this regards are thus worth undertaking, notably in Rwanda, where community empowerment continues to flourish since the adoption of decentralization policy in 2000 .

All the above considerations lead to the study research aims consisting of knowing if and how community empowerment in terms of education or training, resource mobilization and enabling environment plays a role in the improvement of social accountability in decentralized local entities in Rutsiro District, Western Province Rwanda.

\section{Theory of Change}

This study was guided by (Wild and Harris, 2011) this model by describing the way in which action are carried out through involvement play a significant role to the series of findings that stimulate the realization of expected or targeted outcomes (CARE International, 2012). The theory was usually advanced though the planning step, however may be important for follow up and control.

The model of change may give a context for the success of unified description related to the involvement marks specifically helps (Dart, \& Rudland, 2010). The may be very pertinent for sharing information related to involvement to 
potential associates, members and decision makers and for giving a pertinent point of orientation for these included in executing and administrating it.

The main benefit of theory of change emanates from viewing and assuming the change procedure explicit, particularly on the face of it (Ellis, Parkinson \& Wadia, 2011). The aim of making so is to see they adequacy, discuss them and fortify them to enforce research plan and execution.

\section{Social transformational theory}

This research is guided by Social transformation theory. Normally; human society is a process and at all levels of its complexity, it encounters continuous change. The process of social development is full of contradictions and struggle, and so is personal development (Bukenya \& King, 2012) argues that there is a set of criteria that determine if a change is transformative; it could be adjusted through social modification or individual transformation or both; the ultimate goal of adjustment is to analyze a fundamental shift in individual belief and values and could involve a social perspective related to the future relying on value system that are fighting for liberty; democracy or equity; and authenticity; there is a change in skills and knowledge relying on conflict transformational models which predict the difference of interest when people are performing adjustment for individual and meaning or social structure and procedure. Social transformation can significantly facilitate critical self-reflection and the movement in turn can gain great power when people identify themselves as part of their perspective transformation (Funnell \& Rogers, 2011).

\section{Data collection methods}

A descriptive survey design was employing Questionnaires and interviews were used to collect primary data. A descriptive research approach was carried out by use of participatory questionnaires with open ended as well as close questions.

The sample size was calculated through the use of Krejcie \& Morgan's (Creswell, 2009) formula of determining sample size $n=N / 1+(N)(e) 2$. Where $n$ is the sample size, $\mathrm{N}$ is the total population and $\mathrm{e}$ is the marginal error $n=408 / 1+408(0.5) 2$. Approximately 202 respondents.

The researcher sought the 202 respondents is a good number to generalize the findings because most of the previous studies are usually carried out on a sample of subjects rather than the whole population. The key to the fact that 202 is a good sample is that it is typical of the population from which it is drawn. For eliminating exaggerated marginal error, the researcher used randomization process of selecting respondents. In order to reduce the sampling error, the simple random sample technique and a large sample size was developed.

Table 1 the influence of involving citizens in all aspects of their development on social accountability in Rutsiro District

\begin{tabular}{llll}
\hline Statement & N & Mean & $\begin{array}{l}\text { Std. } \\
\text { Deviation }\end{array}$ \\
\cline { 2 - 3 } & Valid & & 0.780 \\
\hline $\begin{array}{l}\text { citizens are invited } \\
\text { to all community } \\
\text { meetings }\end{array}$ & & 4.37 & \\
citizens are \\
describing the basic \\
principles of plan \\
citizens describe \\
community \\
$\begin{array}{l}\text { competitive } \\
\text { advantage } \\
\text { disadvantages and }\end{array}$
\end{tabular}

Source Primary Data 2020

Table 1 revealed that participation in decision making had the highest mean and lowest std. Deviation $(=4.37, s=0.780)$ showing lowest change and strong agreement among answers. It was therefore, noted that the mean for responses for citizens are sharing beliefs and ranged had the lowest mean and highest std. Deviation $(=3.52, \mathrm{~s}=0.995)$. This concur with the statements that participation in decision making, citizens are invited to all community meetings, during a meeting citizens are describing the basic principles of plan, employees describe community competitive advantage and disadvantages and citizens are sharing beliefs and values and citizens are allowed to clarify their intentions about plan influences the social accountability in newly established local entities in Rwanda. This agrees with Shields, Patricia and Rangarjan. (2013) who argued that participation in decision making includes the shared beliefs, norms and values within the community. It sets the basis for strategy. For a strategy within a community to advance and be executed successfully, it must full connect with the participatory approach. Therefore, initiative and objectives must be established within the community to help and ascertain participatory approach that holds the social accountability over time.

UNDP (2013), a local leader faces all kinds of barriers, but the involvement of local people become the ultimate copying strategies to overcome those 
challenges. The researcher further tested whether there is a negative significance between means of participation in decision making and social accountability.

Qualitative findings from an interview between the researcher and local leaders of Rutsiro District show that involving citizens in all aspects of their development in Rutsiro District enhanced the social accountability process in the district.

Therefore, evidences from interviews argue that the citizens are invited to all community meetings, citizens are describing the basic principles of plan, citizens describe community competitive advantage and disadvantages, citizens are sharing beliefs and values, citizens are allowed to clarify their intentions, Discussion from the focus group discussion evidenced that the qualitative findings in relation with the third research objectives support the set objectives. The evidences from the FGDs evidences that the influence of involving to citizens in all aspects of their administration and development lead to higher awareness of development activities, citizens are consulted, leaders held accountable in, Rutsiro District. This stimulates effective social accountability.

Table 2 the Correlation matrix for the relation between and dependent variables

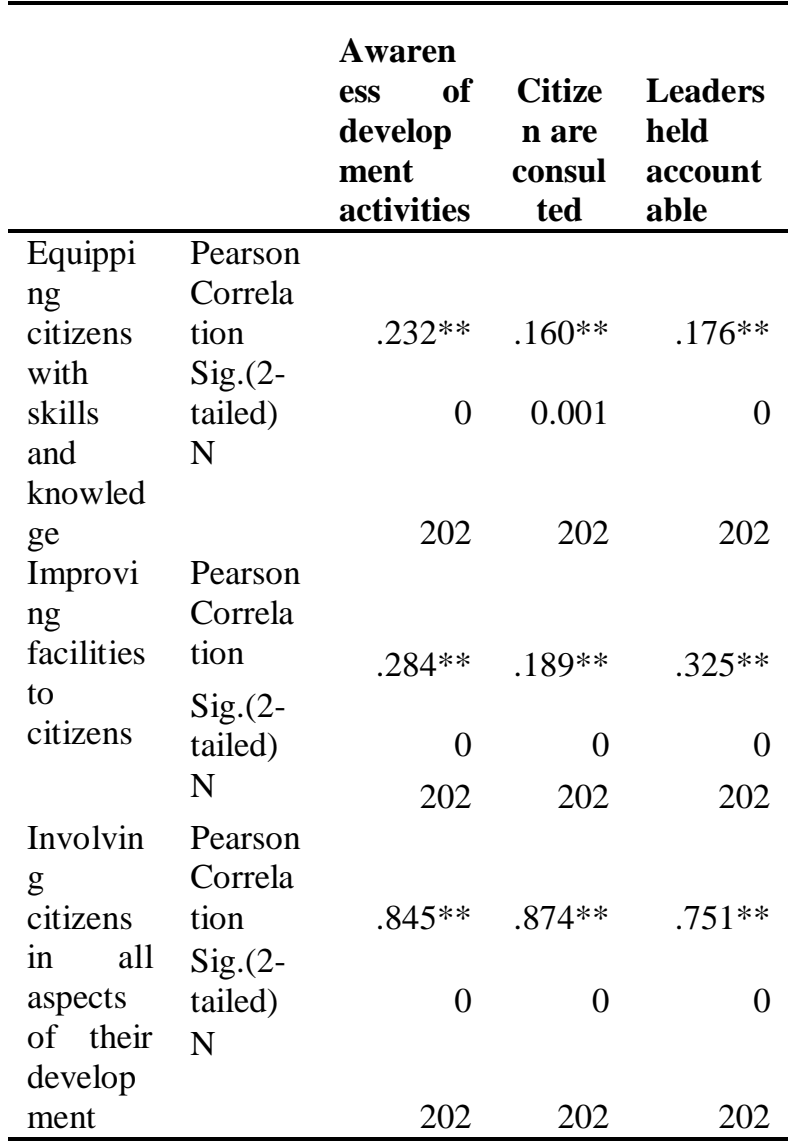

Source Primary Data 2020
Table 2 indicates the correlation matrix between community empowerment (Equipping citizens with skills and knowledge, improving facilities to citizens and involving citizens in all aspects of their development) and social accountability (awareness of development activities, citizens are consulted and leaders held accountable). Results show that equipping citizens with skills and knowledge is positively correlated with leaders held accountable at .176 while improving facilities to citizens is correlated with citizen are consulted. However, involving citizens in all aspects of their development is correlated with awareness of development activities at $.845^{* *}$ with citizens are consulted $874 * *$ and leaders held accountable $751 * *$. However, the above stars imply the positive or high level of significance between the above indicators.

Study findings did not contradict the findings of a study conducted by Scheerens and Creemers, (2009) who found that equipping citizens with skills and knowledge in decentralized local entities have positive correlation with social accountability in developing countries. Results concur with information given by Tshui, and Cai, (2011) who found that improving facilities to citizens, involving citizens in all aspects of their development.

A multilinear regression analysis was utilized to assess the effects of the independent variablecommunity empowerment (equipping citizens with skills and knowledge, improving facilities to citizens and involving citizens in all aspects of their development) on the dependent variable - social accountability. Findings were presented in Tables 1, Table 2 and Table 3

\section{Table 3 Model Summary}

\begin{tabular}{|c|c|c|c|c|}
\hline Model & $\mathrm{R}$ & R Square & $\begin{array}{l}\text { Adjusted } \\
\text { R Square }\end{array}$ & $\begin{array}{l}\text { Std.Error } \\
\text { of the } \\
\text { Estimate }\end{array}$ \\
\hline 1 & $.966 \mathrm{a}$ & 0.933 & 0.932 & 0.28417 \\
\hline
\end{tabular}

a.Predictors: (Constant) Equipping citizens with skills and knowledge, improving facilities to citizens, involving citizens in all aspects of their development.

\section{Source Primary Data 2020}

Results presented in Table 3 argued that $\mathrm{R}^{2}$ of model was .933 with the adjusted R2 $=.932$. The DurbinWatson $\mathrm{d}=.28417$ was between two acute standards of $1.5<2.5$ and was, expected that the predictor of the dependent variable met the assumption and there was lack of linear auto-correlation in information. Thus, $96.6 \%$ of the change in social accountability could be assigned to the independent variables. The implication brought is that $4.4 \%$ of the changes in social accountability could be attributed to other 
factors. Table 3 provides a model summary between the indicators of independent variable dependent. In this regards, the following provides responses for regression coefficients.

Table 4 reflect that, F-test with $F=202$ and 197 degrees of freedom of the test suggested that the test was highly significant, and was thus expected that there was a linear correlation between variables in the model. The probability of 0.000 demonstrated that the model was significant in predicting the effects of community empowerment.

Table 4 Regression Coefficient

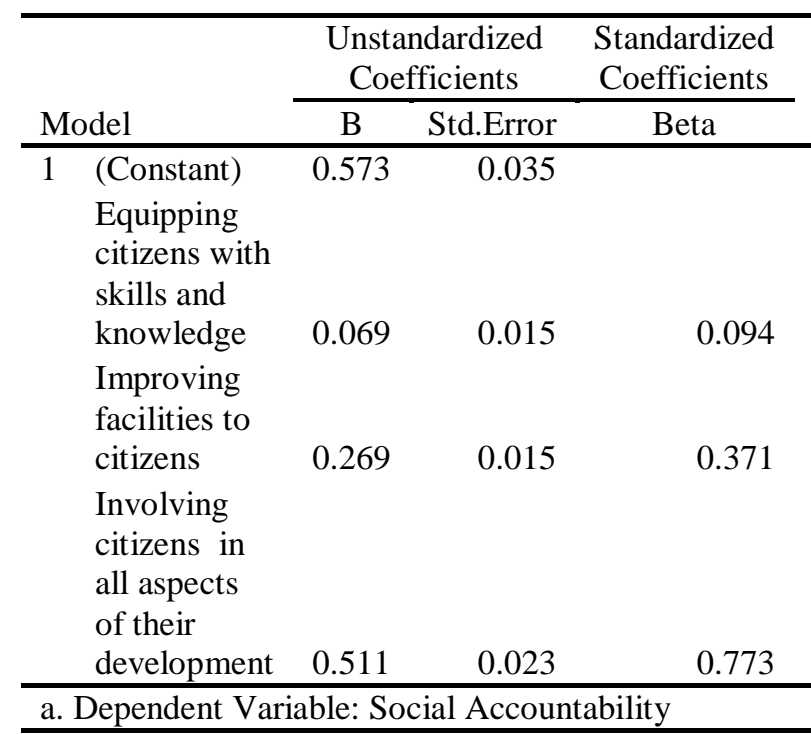

Source Primary Data 2020

The regression model derived from Table 4 was as follows: $\mathrm{Y}=-.573+0.094 \mathrm{X} 1+0.371 \mathrm{X} 2+\quad 0.773 \mathrm{X} 3$, where $\mathrm{Y}$ is social accountability, $\mathrm{X} 1$ is equipping citizens with skills and knowledge

$\mathrm{X} 2$ is improving facilities to citizens, and $\mathrm{X} 3$ is involving citizens in all aspects of their development. The regression model given a statistical control through which the research revealed the effects of each predictor variable. For this research, holding all variables at zero would lead to negative effective of 573 in social accountability. A unit change in equipping citizens with skills and knowledge would lead to 0.094 increments in social accountability when all other independent variables were decreased to zero. A unit change in improving facilities to citizens would lead to 0.371 .

The same, a unit change in involving citizens in all aspects of their development lead to 0.733 increments social accountability when all independent variables were decreased to zero. The findings demonstrated that the coefficient for each independent variable were zero. This meant that all independent variables influenced the dependent variables.

\section{Conclusion}

Involving citizens in all aspects of their development is correlated with awareness of development activities at $.845 * *$ with citizen are consulted $874^{* *}$ and leaders held accountable $751^{* *}$. Thus, government must put much efforts for shared understanding of needs and local priorities, training, effective communication and participation in decision making. Therefore, citizens must be committed to participate actively to the social accountability in order to achieve effective proposition and solutions and policies are shadowed to attain its ultimate goals.

\section{Tcknoigledgement}

16283ish t0 acknowledge Dr. Ernest Safari for her contribution to this work from the beginning up to it's the completion. I also wish to extend my acknowledgement to the Mount Kenya University, 4 Rgg giro District authorities for their support and collaborative in terms of data collection.

\section{References}

[1] Aaron, R. (2003). 'Improving Educational Quality through Enhancing Community Participation', Banding University Press. Indonesia.

2\$220Bukenga, B \& King, S. (2012). 'The contextual factors for demand-side social accountability an anmotated Bibliography produced for the Social Accountability and Demand for Good Governance Cluster at the World Bank,

[3] Creswell, J.W. (2009). Research Design Qualitative, Quantitative and Mixed Methods Approaches, 3rd ed. Sage Publications, Los Angeles - London - New Delhi - Singapore. D.C. Development Studies.

[4] Dart, J., Hall, J., \& Rudland, E. (2010). Evaluation of Asiad's Engagement with Civil

[5] Ellis, J., Parkinson, D., \& Wadia, A. (2011). Making Connections: Using a theory of change to develop planning and evaluation. Charities Evaluation Services

[6] Funnell S \& Rogers P. (2011). Purposeful Program Theory: Effective Use of Theories of Change and Logic Models, Jossey Bass Whiley, UK.

[7] Lieberman, E, Posner, D \& Tsai, L. (2013). 'Does Information Lead to More Active Citizenship? Evidence from an Education Intervention in Rural Kenya' March 5, MIT Political Science Department Research Paper no. 2, Princeton University Press, USA.

[8] Mapuva, J. (2015). Citizen Participation, Mobilization and Contested Participatory Spaces. 
International Journal of Political Science and Development, 405-415.Bindura University Press. Bindura-Zimbabwe.

[9] National Institute of Statistics for Rwanda (2014). Integrated Household Living Conditions Survey 4 (EICV 4), Kigali. Rwanda

[10] O’Meally, S. (2013). 'Mapping Context for Social Accountability, A Resource Paper', Social Development Department, World Bank,

[11] Scheerens and Creemers, (2009). Improving market access and agricultural productivity growth in Africa: what role for producer

\section{ISSN 2455-6378}

organizations and collective action institutions? Food Security, 3(4), 475-489.

[12] Shields, Patricia and Rangarjan. (2013). A Playbook for Research Methods: Integrating Conceptual Frameworks and Project Management. New Forums Press, 24.

[13] Tshui,M and Cai, R (2011). 'Empowering Parents in Schools: What They Can (not) Do', MIT Boston, US,

[14] Wild, L \& Harris, D. (2011), 'The political economy of community scorecards in Malawi. World Bank. New York.

USA. 